\title{
Thermodynamic Performance Assessment of Ozone Layer Friendly Natural Refrigerants as Potential Substitutes to HCFC's
}

\author{
M. Boumaza
}

\begin{abstract}
Due to the environmental concerns related to ozone depletion potential (ODP) and global warming potential (GWP) of the existing refrigerants, industry and researchers in this field are investigating long-term solutions. With extensive work on alternatives to chlorofluorocarbons (CFCs) and hydro chlorofluorocarbons (HCFCs), initially hydro fluorocarbons were considered to be long-term solutions. The global warming of HFCs has become a hurdle to accept them as long-term solutions. Now, the focus is on the use of natural refrigerants like hydrocarbons (HCs) such as R290, R600, ammonia, carbon dioxide and water. These natural substances have very low GWP, and a zero ODP.

This paper presents thermodynamic performance analysis of $\mathbf{R} 22$ and three of its alternatives natural refrigerants (R290, $\mathrm{R600a}$ and $\mathrm{R717}$ ) for $\mathrm{A} / \mathrm{C}$ and refrigeration purposes, through a simulation model. The investigation enables to confirm the possibility of using these natural refrigerants as a substitute to R22.
\end{abstract}

Index Terms-Refrigerants, performance, ozone layer, friendly.

\section{INTRODUCTION}

As per the Montreal protocol, the Chloro fluorocarbons (CFC's) have already been phased out in the developed countries, while the hydro chloro fluorocarbons (HCFC"s) should also be phased out by 2017 .

During the last two decades, the number of refrigerants likely to be used in refrigerating machines has dramatically increased as a consequence of the elimination of these refrigerants.R22 (HCFC 22) is one of the important refrigerant used in air conditioning all over the world. R22 is controlled substance under the Montreal Protocol. It has to be totally phased out by 2017.

HCF 22 replacements options for $\mathrm{A} / \mathrm{C}$, heat pumps and refrigeration systems can be grouped in three categories, Fluorocarbons that are used in conventional vapor compression cycles such as R134a, R410a, R407C, alternatives fluids which include propane R290 and R717 and are also used in vapor compression cycles, and finally alternatives cycles that include absorption systems, and use Tran critical fluids $\left(\mathrm{CO}_{2}\right.$ and $\left.\mathrm{R} 744\right)$ and air cycle. In general these alternative technologies do not currently offer the same energy efficiency as the vapor compression cycle.

Several investigations have been carried out in order to

Manuscript received December 16, 2013; revised March 21, 2014.

M. Boumaza is with the Department of Chemical Engineering, College of Engineering, King Saud University, Riyad, Saudi Arabia (e-mail: muradbza@gmail.com). determine the efficiency of potential substitutes to R22.Reference [1] compared the performances of R22 and R 410A working at elevated condensing temperatures up to 60 . Reference [2] explored some of the advantages and disadvantages of R 410A, and other substitutes to R22. While [3] have provided working characteristics to optimize the components of the refrigerating machines. Some reported research [4]-[7] concerned specific outdoor temperatures, as well modifications of the refrigeration compression cycle, while [4] carried out a review of potential substitutes to R22 and their performances. Reference [8] as well other researchers [9]-[11] have presented a performance evaluation of R290 and other natural refrigerants as a drop substitute to R22 in a air conditioning applications.

Reference [12] have studied the evaporation process of several potential substitutes to CHF's and HCFC's inside horizontal smooth tube, while [13] have investigated a retrofit for CFC12 systems using mixture of R134a/ R600a and HC290. Recently [14], [15] have carried out a comparative experimental study of piston compressor using R1324YF, R134a and R290, while [16], [17] compared the performance of vapor injection cycles using R410a and R32.

One of the main important parameters in choosing new refrigerants, concerns the graph which represents a plot of the saturated vapour against the temperature. This is due to the operating conditions which require the knowledge of the maximal and minimal vapour pressures. Thus it is required to avoid refrigerants which exhibit very low vapour pressure (below atmospheric pressure) at low temperatures in order to avoid air infiltration., while low ratio of compression can be considered as a positive parameter, as it enables to increase the efficiency cycle by reducing the energy consumed by the compressor. A plot of the saturated vapour pressures against the temperatures for the R22 and its potential substitutes is shown in Fig. 1. It can be seen that R407c has nearly the same pattern as R22, while R404A has higher pressure, and R410 which is a high pressure fluid, possess a low critical temperature, and finally R134a possess a lower pressure than R22

This paper presents comparative thermodynamic analyses of R22 and three of its alternatives natural refrigerants (R290, $\mathrm{R} 600 \mathrm{a}$, and $\mathrm{R} 717$ ) for $\mathrm{A} / \mathrm{C}$ and refrigeration purposes operating under both high and low outdoor temperatures, for a refrigerating machine using basic vapor compression cycle. These natural substances have the dual advantage of very low global warming, nearly zero and zero depletion as shown by Table I which represents the environmental data of some selected refrigerants. 


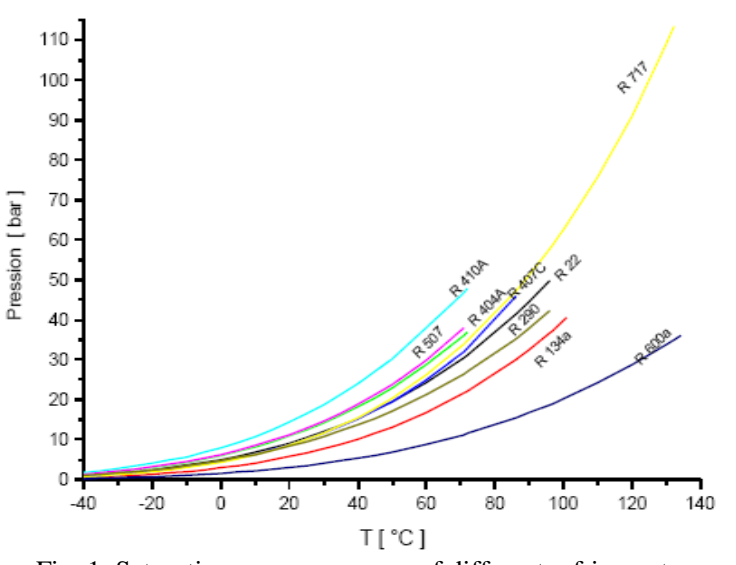

Fig. 1. Saturation vapor pressures of different refrigerants.

TABLE I: EXPERIMENTAL DATA OF SOME REFRIGERANTS

\begin{tabular}{|l|l|l|}
\hline Refrigerants & ODP & $\begin{array}{l}\text { GWP (time horizons of } \\
\mathbf{1 0 0 y e a r s})\end{array}$ \\
\hline $\mathrm{CFC} 11$ & 1 & 4600 \\
$\mathrm{CFC} 12$ & 0.82 & 10600 \\
$\mathrm{HCFC} 22$ & 0.034 & 1700 \\
$\mathrm{HCFC} 123$ & 0.012 & 120 \\
HFC134a & 0 & 1300 \\
$\mathrm{HFC152a}$ & 0 & 120 \\
R407C & 0 & 1700 \\
R410A & 0 & 2000 \\
$\mathrm{HC} 290$ & 0 & 20 \\
$\mathrm{HC} 600 \mathrm{a}$ & 0 & 20 \\
R717 & 0 & $<1$ \\
Water & 0 & $<1$ \\
$\mathrm{CO}_{2}$ & 0 & 1 \\
\hline
\end{tabular}

The study enables to determine the effect of the condenser and evaporator temperatures on the coefficient of performance, the volumetric refrigerating capacity, as well as the compressor discharge temperature. These results provide an acceptable comparison of the thermodynamic performance of R22 and four of its potential substitutes.

\section{REFRIGERATION CYCLE}

The refrigeration cycle studied is a standard vapor compression cycle composed mainly of four main equipments: evaporator, compressor, Condenser and an expansion valve as illustrated in Fig. 2.

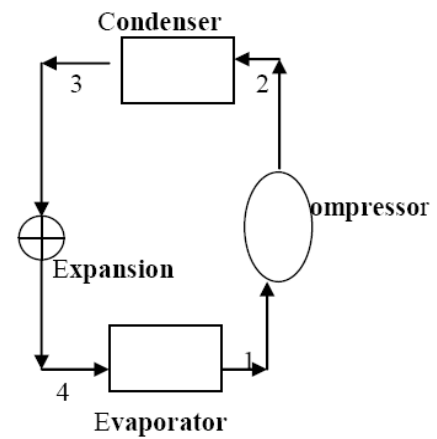

Fig. 2. Standard vapour compression cycle.
The following assumptions are made:

- An evaporation at constant pressure, in the evaporator with an evaporator temperature, Tev, from point 4 to point $1\left(h_{4}\right.$ to $\left.\mathrm{h}_{1}\right)$.

- An adiabatic isentropic compression process in the compressor, from $P_{1}$ to $P_{2}$, corresponding to point 1 and point $2\left(h_{1}\right.$ to $\left.h_{2}\right)$.

- A de superheating process at constant pressure followed by a condensation at constant temperature $(T c)$ and pressure in the condenser, from point 2 to point 3 . $\left(h_{2}\right.$ to $\left.h_{3}\right)$.

- An expansion at constant enthalpy in the throttling valve, corresponding from point 3 to point $4\left(h_{3}=h_{4}\right)$.

The vapour leaving the evaporator as well as the liquid leaving the condenser are supposed to be at saturated states, and therefore neither superheating of the vapour nor sub cooling of the liquid are required.

\section{MODELLING BASIS}

A Simulation model was developed in order to investigate the effect of the evaporator and condenser temperatures (representing the ambient temperatures) on the coefficient of the performance of the cycle (COP), the volumetric refrigerating capacity (VRC), the compressor discharge temperature (Tcomp), and the compressor load capacity.

The required data for the model are:

- Specifying the nature of the refrigerant by fixing the physical and thermodynamics properties.

- Fixing the evaporator and condenser temperatures.

- Fixing either the mass flow rate of the refrigerant or the refrigeration capacity.

The model enables to estimates the evaporator and condenser pressures (Pev and $\mathrm{Pc}$ ), the compressor discharge temperature (Tcomp), as well as the different enthalpies involved in the cycle.

The thermodynamic and transport properties of the refrigerant are determined through chemical thermodynamics relations. Mass balances and energy balances are used to derive expression for the Coefficient of Performance and the refrigeration capacity.

For the cycle studied, the main mechanical power supplied to the system is supposed to be the power supplied to the compressor, Pcp [12].

Mass flow rate of the refrigerant; is determined as follows:

$$
\begin{gathered}
M r=\frac{Q r}{h_{2}-h_{1}} \\
h_{1}=h_{4}
\end{gathered}
$$

- Energy required in the compressor (load)

$$
Q_{c p}=M_{r}\left(h_{3}-h_{2}\right)=Q_{r}\left(\frac{h_{3}-h_{2}}{h_{1}-h_{4}}\right)
$$

- Energy liberated in the condenser 


$$
Q_{c d}=M_{r}\left(h_{3}-h_{4}\right)=Q_{r}\left(\frac{h_{3}-h_{2}}{h_{1}-h_{4}}\right)
$$

- Volumetric Flow rate (VRC)

$$
G=\frac{Q_{r}}{q_{r}}=M_{r} v_{a}
$$

$q_{r}=$ Specific volumetric refrigeration load,

- Coefficient of the performance, COP

The coefficient of Performance, (efficiency of the cycle), COP defined as,

$C O P=$ Refrigeration load / compressor load

$$
C O P=\frac{Q_{R}}{Q_{C P}}=\frac{h_{2}-h_{4}}{h_{3}-h_{4}}
$$

- The COP of the ideal cycle can be defined as follows

$$
C O P_{\text {ideal }}=\frac{T_{e v}}{T_{e v}-T_{C}}
$$

- Saturated pressure

The empirical equations proposed by Lee and Kesler [18] is used in this study to estimate the saturated pressures, which is as follows

$$
P_{s a t}^{+}=f^{0}\left(T_{r}\right)+w \cdot f^{1}\left(T_{r}\right)
$$

$P_{\text {sat }}=$ Reduced Pressure at the saturation liquid vapour

$$
P_{s a t}^{=}=\frac{P_{s a t}}{P_{c r}}
$$

$f^{0}=$ relative fugacity at zero order $(w=0)$

- Determination of the pressure at the end of compression For an adiabatic compression and an ideal gas

$$
P . V^{\gamma}=\text { cons } \tan t
$$

$\gamma=\mathrm{Cp} / \mathrm{Cv}$; calculated at one atmosphere and 30C

- Using the ideal gas law and the temperature, equation (10) becomes,

$$
P . T^{\frac{\gamma}{\gamma-1}}=\text { cons } \tan t
$$

\section{RESULTS}

The calculations were performed for three potential substitutes to R22, as well as R22, by considering three different condensing temperatures, and investigating the effect of the evaporator temperatures on the coefficient of performance, the volumetric refrigerating capacity the compressor load and the discharge temperature.

\section{A. Coefficient of the Performance (COP)}

Fig. 3 (a-c) show the variation of the $\mathrm{COP}$ with various evaporating temperatures ranging from $-30^{\circ} \mathrm{C}$ to $10^{\circ} \mathrm{C}$, and for three condensing temperatures $\left(30^{\circ} \mathrm{C}, 40^{\circ} \mathrm{C}, 50^{\circ} \mathrm{C}\right)$, for the alternatives refrigerants considered, as well for the R22. It can be seen from these figures that the COP varies linearly with the evaporator temperature for all the cases studied.

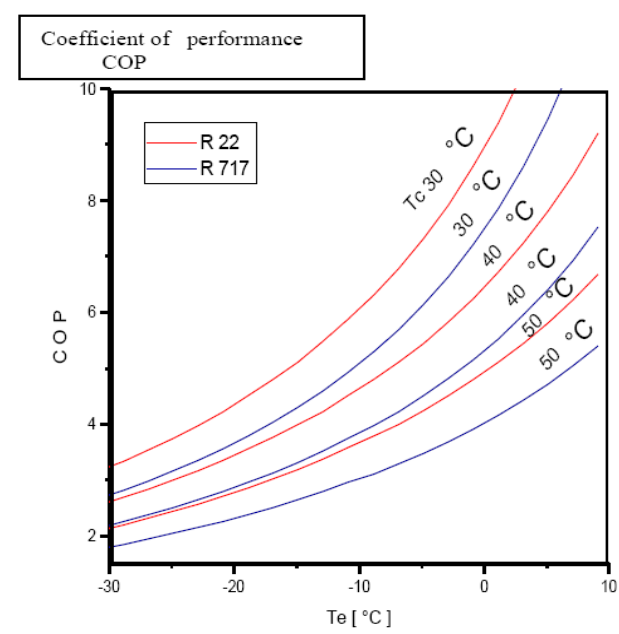

(a)

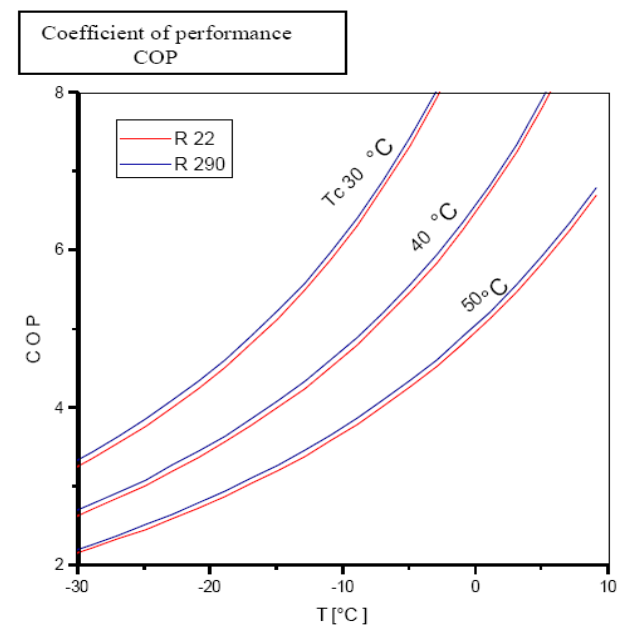

(b)

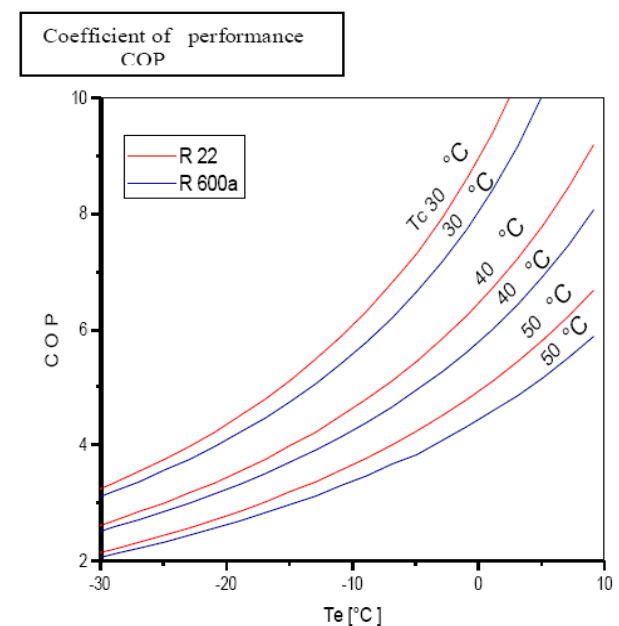

(c)

Fig. 3. Variation of the COP with respect to Tev and Tcond, for the new refrigerants and R22. a) R22 / R 717 , b) R22 / 290, c) R22 / 600a.

R 290 seems to be similar to R22, showing similar trends and similar variation for all the cases studied. Ammonia and 
R600a exhibits smaller COP than R22, when operating under similar conditions.

\section{B. Volumetric Refrigerating Capacity}

Fig. 4a-Fig. 4c show the effect of the evaporating temperatures on the volumetric refrigerating capacity (VRC) for three condensing temperatures $\left(30^{\circ} \mathrm{C}, 40^{\circ} \mathrm{C}\right.$ and $\left.50^{\circ} \mathrm{C}\right)$.

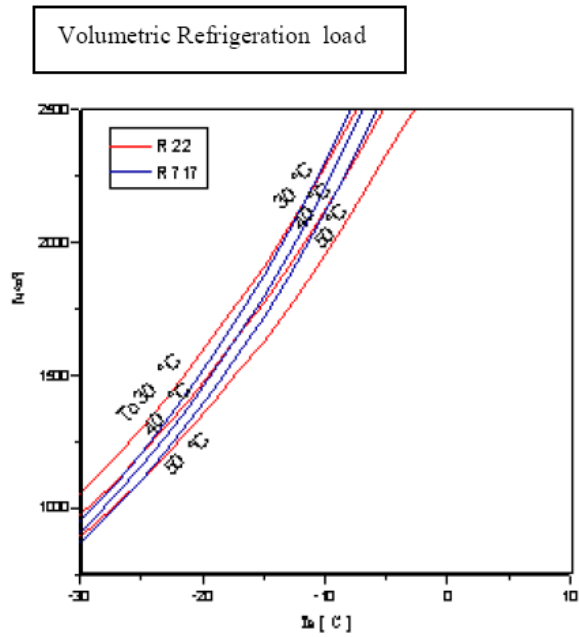

(a)

Volumetric refrigeration load

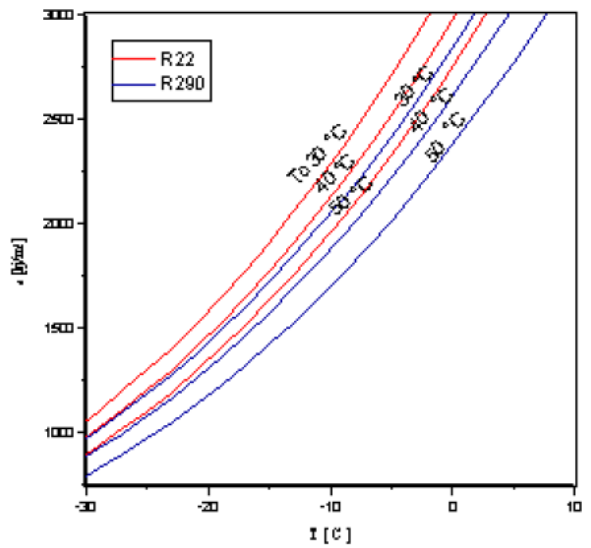

(b)

Volumetric Refrigeration load

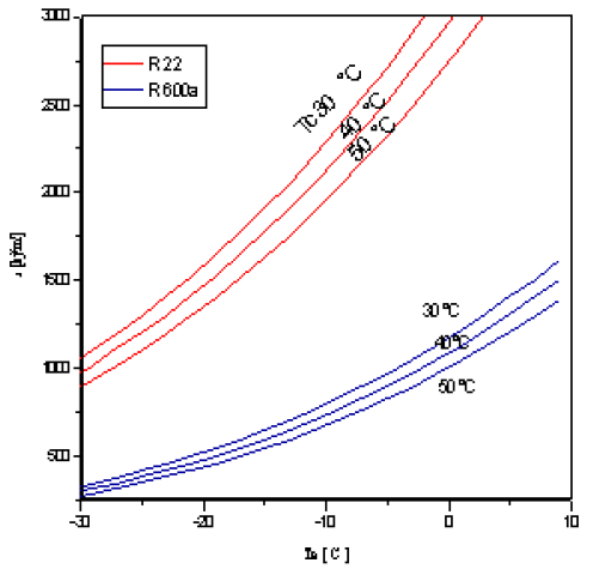

(c)

Fig. 4. Variation of the volumetric refrigerating capacity of the new refrigerants studied and R22 with respect to Te and Tc . a) R22 / R 717 , b) R22 / 290, c) R22 / 600a.

It is seen that R290 which has a critical temperature below $10^{\circ} \mathrm{C}$, exhibits value of VRC close to the R22 values, for the three condensing temperatures considered. R600a gives lower values of VRC, while ammonia on the hand show larger values of VRC, compared to R22, but these values start decreasing the evaporator temperatures decrease.

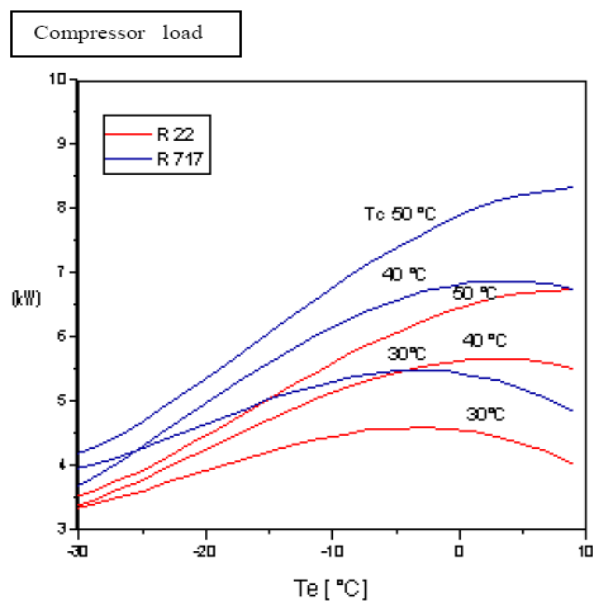

(a)

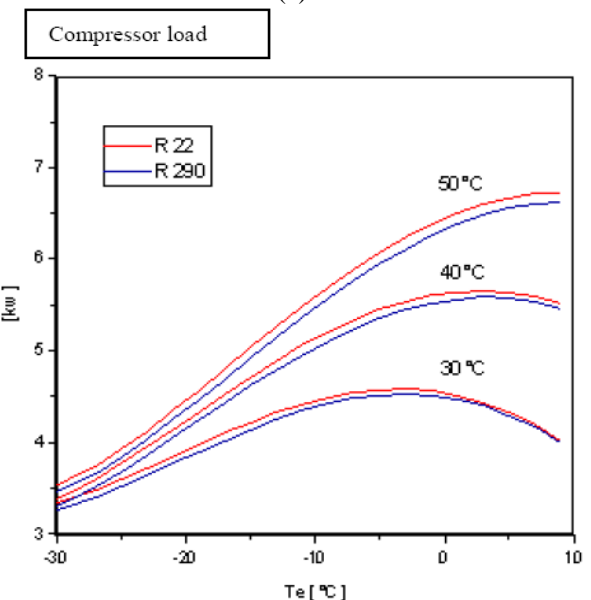

(b)

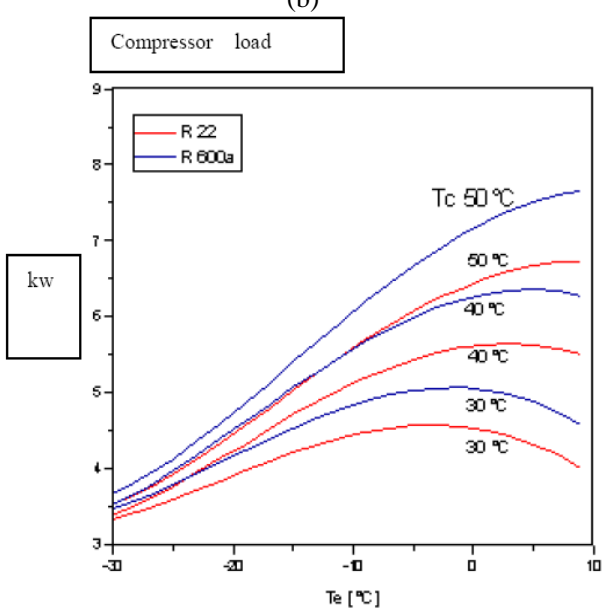

(c)

Fig. 5. Variation of the compressor load with respect to Tev and Tcond for the new refrigerants and R22., a) R22 / R 717 , b) R22 / 290 , c) R22 / 600a.

\section{Variation of the Compressor Load}

Fig. 5a-Fig. 5c show the variation of the compressor load with respect to the evaporator temperatures for three different condensing temperatures $\left(30^{\circ} \mathrm{C}, 40^{\circ} \mathrm{C}, 50^{\circ} \mathrm{C}\right)$. It is well known that the pressures have a direct impact on the performance of the cycle, moreover, the le lower the pressure ratio, the less energy is required to drive the compressor. It can be seen from 
these figures that R290 show a slightly lower values than R22, while ammonia and R600a exhibit respectively a higher value of $22 \%$ and $10 \%$ than R22.

It can be seen from this analysis, that ammonia possesses very interesting thermodynamic properties, such as its high latent heat but it exhibits dangerous properties such as its flammability, toxicity, and therefore the direct substitution of R22 to ammonia requires important changes to the existing equipment in order to resist ammonia.

R290 has physical properties and thermodynamic performances similar to R22, but with lower flow rate, and therefore requiring smaller equipment. This suggests its recommendation as a potential substitute to R22.

$\mathrm{R} 600$, which is a flammable refrigerant but less harmful to environment, can also be a potential substitute to R22, despite its lower thermodynamic performance.

\section{CONCLUSIONS}

It is evident that today, several new refrigerants whether pure, mixtures or naturals, are proposed to replace R22. R290 (propane), R600(iso butane) and R717 (ammonia), which are considered natural refrigerants, seem to be the best potentials candidates to use refrigeration, air conditioning and heat pumps. Beside being environmental and ozone layer friendly substances, new lubricants have also been developed to operate with these refrigerants [17], [18].

The present analysis has enabled to show that:

- Performance of vapour compression system decreases with increasing outdoor temperatures.

- R 290 may be directly used a substitute to R22, for smaller refrigeration load.

- Ammonia which possess excellent thermodynamic performance, and covers a wide range of refrigeration temperatures, both positive and negative, requires specific materials due to its dangerous physical properties.

- R600a, an environmental friendly refrigerant possesses a low vapour pressure and provides therefore a low refrigerant load. It can be used for domestic refrigeration, requiring a positive refrigeration.

- Fluids having low critical temperature exhibit an important decrease in cooling capacity.

- Rate of compressor power increase is similar for all fluids.

- The new refrigerants studied have lower compressor discharge temperatures than the R22, and therefore will require compressors operating under less sever conditions.

\section{NOMENCLATURE}

\section{$h$ : Enthxalpy $(\mathrm{KJ} / \mathrm{kg})$}

$M r$ : Mass flow rate of the refrigerant $(\mathrm{kg} / \mathrm{sec})$

$P_{\text {cond }}$ : Condensing Pressure (Bar)

$P_{e v}$ : Evaporator Pressure (Bar)

$P_{\text {sat }}:$ Saturated pressure (atm)

$P_{c r}$ : Critical pressure (atm

$T_{\text {cond }}$ : Condensing temperature $(\mathrm{C})$

$T_{e v}$ : Evaporator temperature (C)
$T_{\text {comp }}$ : Compressor discharge temperature $\left({ }^{\circ} \mathrm{C}\right)$

$V$ : Volume $\mathrm{m}^{3}$

$\gamma$ : Ratio of the specific heat constant $(\mathrm{Cp} / \mathrm{Cv})$

\section{REFERENCES}

[1] C. Meurer, O. Buyle, and M. P. Lanckriet, "Comparison of R22 and R410a at elevated condensing temperatures," in Proc. 20th Int. Congress of Refrigeration, Sydney, August 1999.

[2] L. Chin and M. W. Spatz, "Issues relating to the adoption of R410 an in air conditioning systems," in Proc. 20th Int. Congress of Refrigeration, Sydney August 1999.

[3] A. Benamer and D. Clodic, "Test bench for comparative measurement of energy efficiency of variable and fixed speed scroll compressor," in Proc. 20th Int. Congress of Refrigeration, Sydney August 1999.

[4] S. F. Y. Motta and P. A. Domanski, "Performance of R22 and its alternatives working at high outdoor temperatures," in Proc. 8th Int. Refrigeration Conference, West Lafayetet, USA, 2000.

[5] N. A. Roberts, "Determination of the performance, leak scenario flammability, and oil return characteristics of a novel R22 replacement," in Proc. 8th Int. Refrigeration Conference, Purdue University, West Lafayetet, USA, 2000.

[6] N. A. Roberts and S. H. Jawad, "Investigation of the vapour-liquid equilibrium behaviour of blends comprising R125, R134a, and R600 or R600a," in Proc. 8th Int. Refrigeration Conference, Purdue Universitu, West Lafayetet, USA, 2000.

[7] E. Baumont, M. Frere, and A. Pilatte, "Simulation of refrigerating machines, influences of the heat exchangers design for low refrigerant charges pn the working point," presented at Zero Leakage Conference, Int. Institue of Refrgeration, Stockolm, 2002.

[8] S. Devotta, A. S. Padalkar, and N. K. Sane, "Performance of HC 290 as a drop -in substitute to HCFC 22 in a window air conditioner," Int. Journal of Refrigeration, vol. 28, no. 4, 2005.

[9] S. Devotta, A. V. Waghmare, and B. M. Sawant, "Alternatives to HCFC -22 for air conditioners," Applied Thermal Engineering, vol. 21, no. 6, 2001

[10] Y. Hwang, A. Gado, and R. Radermacher, "Performance propane in a unitary heat pump," in Proc. $21^{\text {st }}$ Int. Congress of Refrigeration, Washington, USA, August 2003.

[11] G. Lorentzen, "The use of natural refrigerants, a complete solution to CFC/HCFC," Int. Journal of Refrigeration, vol. 18, no. 3, 1995.

[12] M. A. Hussain, Y. Onaka, and H. Afraz, "Heat transfer during evaporation of R1234 and R32 inside a smooth tube," Int. Journal of Refrigeration, vol. 36, no. 2, pp. 325-334, 2013.

[13] S. J. Sekkar and D. M. Lal, "HFC134a/HC600a/HC290 mixture a retrofit for CFC12 systems," Int. Journal of Refrigeration, vol. 28, no. 5, pp. 735-743, 2005.

[14] E. Navarro, I. O. M. Galvon, J. Nohales, and J. Gonzalves, "Comparative experimental study of an open piston compressor working with R-1324yf, R-134 and R290," Int. Journal of Refrigeration, vol. 36, no. 3, pp. 768-77, 2013.

[15] E. Navarro, I. O. M. Galvon, J. Nohales, and J. Gonzalves, "Experimental analysis of R-1234YF as a drop in replacement for $\mathrm{R} 134 \mathrm{a}$ in a vapour compression system," Int. Journal of Refrigeration, vol. 36, no. 3, pp. 870-880, 2013.

[16] X. Xu, Y. Hwang, and R. Radermacher, "Performance comparison of R410a and R32 in vapour rejection cycles," Int. Journal of Refrigeration, vol. 36, no. 3, pp. 892-902, 2013.

[17] J. B. Copetti, M. H. Macagnan, and F. Zimani, "Experimental study on R-600a boiling in 2.5mm tube," Int. Journal of Refrigeration, vol. 36, no. 2, pp. 325-334, 2013.

[18] J. M. Smtith et al., Introduction to Chemical Engineering Thermodynamics, 7th ed., Mac Graw Hill 2005, ch. 12, pp. 430-456.

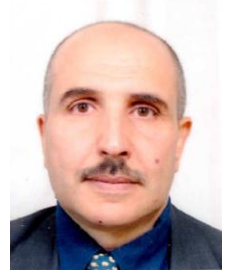

M. Boumaza holds bachelor, master and $\mathrm{PhD}$ degrees in chemical engineering, from Bradford University, England. He is currently a professor in chemical engineering, at King Saud University, Saudi Arabia. Dr. M. Boumaza has published several papers related to energy, cryogenic engineering, refrigeration, water recycling and ammonia plants. He is currently an associate member of IchemE (G.B) and IIF. 